\title{
Presidential review of 2012
}

We live in complex, changing and challenging times. The leaders of our country are trying to manage a somewhat troublesome adolescent stage of our new democracy, while at the same time we are feeling the effects of a fragile international economy.

The health industry in South Africa is witnessing changes in both the public and private sectors. The National Department of Health has been tasked by government with the introduction of a national health insurance plan against a background of limited resources. The private health sector is facing a widening gap between the cost of providing a continued high level of healthcare services and the real, or alleged, ability of medical scheme members to pay for the services.

Against this background, I report on the activities of the RSSA over the last 12 months.

The Society proudly represents over $95 \%$ of the registered radiologists in South Africa, Namibia and Botswana. We have received a request from The Association of Radiologists and Radiotherapists of Zimbabwe for member status of the RSSA for their diagnostic radiologists. This request will be tabled at the next Council meeting in early 2013, and I have no doubt it will be approved in principle, after which the necessary amendments to our Constitution will need to be drafted.

The Council is the policy- and decision-making arm of the Society, and in recent times has met once a year. Between Council meetings, the work of the RSSA is done and managed by the Executive Committee, special interest groups and sub-committees, with assistance from the Medical Director and the Secretariat.

Election of office bearers is held biennially, with the next election to be held in 2013 .

\section{Membership}

At this stage, there are 690 paid-up members of the RSSA, of whom 90 are in government employment, 400 in private practice, and 70 retired/overseas members, and it is pleasing to note there are 130 registrar members. I thank all members for their continued financial contribution to the running of the business of the RSSA. The annual subscriptions are not insignificant, but the role played and status acknowledged in the corridors of the health industry in South Africa bear witness to the value that is added by the Society.

\section{International Affiliation}

The RSSA is enjoying increased affiliation with international counterparts. We continue to be members of the International Society of Radiology and enjoy the ongoing GORAD co-operation. The RSSA is now also an official member of the African Society of Radiology. The aims of the ASR are 'To encourage and promote the development of Radiology in Africa, this being achieved through several activities such as meetings, publications, exchanges, prizes, bursaries, missions and any other adopted way'. Recent activity and participation has been by Savvas Andronikou in Egypt and Thami Mngoma in Kenya.

We continue to enjoy our association with the European Society of Radiology, and I am pleased to report that Professor Gabriel Krestin, President of the ESR, attended the RSSA-SASPI meeting in Sandton. ESR has generously opened up their educational programmes to the
RSSA. Our society has been invited to present 'ECR meets South Africa' at the 2013 ECR. A sub-committee headed by Zarina Lockhat is arranging the marketing and related activities. Attendance by South Africa radiologists at ECR in 2013 is encouraged.

We are now a member of the America Roentgen Ray Society Global Partnership, and the RSSA receives and distributes to members one electronic American Journal of Radiology article per month. The ARRS selects one article from each $S A J R$ and reviews it for possible inclusion in an issue of the $A J R$.

Under the auspices of the CME Association, we are affiliated to the Visiting Professors Program of the Medical Imaging Partnership.

\section{Academic training}

We have 10 teaching campuses in South Africa, providing formal training of radiologists. On average, approximately 30 registrars qualify each year and, at any stage, about 150 registrar radiologists are undergoing training. Under the guidance of Coert de Vries, our Academic representative on Council, a unified curriculum has been established and, although not yet formally adopted, it is used as a guideline by the universities. The quality of training of our new radiologists remains the cornerstone of continued value added by our profession in the medical work-up of patients, and our thanks and appreciation go to all our colleagues who have dedicated their careers to the teaching of others. Special thanks to Professor Savvas Andronikou who is President of the College and plays a significant role in teaching and initiating registrar research.

\section{Continuing medical education}

Leon Janse van Rensburg, the congress chairman of the RSSA, needs no introduction. The RSSA-SASPI congress was one of the most successful to date, and we again have the privilege of attending another world-class radiology congress. While the Society has for many years arranged local congresses for the radiology community, it is over the last 5 years that Leon has taken this portfolio to a level that is the envy of most countries and radiology societies the world over. For all the right reasons, congress activities are now housed in a separate legal entity - the RSSA-CME Association, a not-for-profit organisation - meaning that any surplus funds generated by CME activities are used only to further its clear objectives. Our Radiological Society is a beneficiary of the CME Association in that we benefit from the latter's activities. The CME Association is managed by its designated 'founders': Leon, Zarina Lockhat, Johan Basson and Thami Mngoma. Thanks and congratulations to Leon and his committee for the tireless, outstanding and selfless effort they put into arranging the CME activities.

\section{South Africa Journal of Radiology}

Our own journal, with 4 editions published per annum, continues to showcase important research and enlightening cases from both the academic and private sectors. Editor Jan Lotz works tirelessly to ensure the high quality of the journal, and this year was joined in his efforts by sub-editor Dr Razaan Davis. The journal is published by the SAMAaffiliated Health and Medical Publishing Group, who take the financial 
risk and reward of the publication. There are now 4 international advisers to the $S A J R$, who give positive feedback, noting however that we need to improve the ratio of research articles to case reports. The affiliation with the GORAD initiative of the ISR has increased the exposure of the journal. The current journal size of 40 pages is optimal and can be maintained. The journal is sent out to 650+ members of the RSSA free of charge. A big Thank You to Jan for his continued editorship of our journal.

\section{The government sector}

The government has instructed the National Department of Health to proceed with the implementation of national health insurance (NHI). The provision of healthcare services to the uninsured population in many parts of the country is sub-optimal, with severe shortages of basic facilities and trained management, systems and staff. We agree that the government must embark on a programme to uplift the provision of healthcare to those reliant on state services, but urge the government to ensure that any new interventions are achievable, affordable and sustainable. The first phase of the NHI initiative started this year and includes an audit of state healthcare facilities and resources, and the development of policy and legislative reform. Also included is a pilot project that will see the introduction over the next 5 years of primary healthcare programmes in 10 of the poorest and most underserviced areas around the country, selected because most of them have no access to basic services such as piped water, electricity and refuse removal. The Minister of Health has advised that the focus of all these interventions is to ensure that South Africans have access to quality health services, and experience a reduction in the burden of disease, particularly that borne by women and children.

The RSSA submitted comment on the Green Paper in December 2011, and is now in the process of forming a NHI sub-committee to work with, and make further proposals to, the government NHI policymakers.

\section{Health Professions Council of South Africa}

The Exco has over the last 2 years intervened in and halted a process at the HPCSA that would have seen permission granted for other specialists to own and operate imaging equipment, and formally provided a report on the findings. Upon request of the HPCSA, the RSSA has recently tabled policy guidelines for radiographers performing IV cannulation under the responsibility of a radiologist, as well as policy documents on mammography and CT scanning.

The RSSA issued a formal complaint to, and is still waiting for, the HPCSA to take action in respect of its own findings regarding a breast surgeon reporting on mammography examinations on equipment owned by him.

\section{Imaging guidelines}

The RSSA concluded an agreement with the American College of Radiology to use and amend the ACR Appropriateness Guidelines for Radiology for local conditions and local distribution. The content has been converted into an interactive electronic format, and a web link has been distributed to the funders and members of the society. The guidelines give both clinical and billing appropriateness ratings.

\section{Coding and tariffs}

As you are all aware, there is currently no officially published coding structure or related 'reference price list'. Owing to court action, and scrutiny by the Competition Commissioner, the Department of Health has ceased to be the custodian of the Reference Price List (RPL). The industry is still using the coding structure developed in 2004, which is clearly outdated and in many cases no longer properly reflects imaging practice. Over the last 2 years, the medical aids have announced their own individual tariff increases, and practices now have to deal with an ever-increasing complexity of prices and benefit structures. We are hamstrung by the rules of the Competition Commissioner and may not enter into any collective bargaining arrangements. It is our view that the absence of a RPL and an up-to-date tariff coding structure is counter-productive to properly priced medical services, and we await the outcome of the Minister of Health's discussions with the Competition Commissioner in this regard. The many years of costbased tariff determination projects have come to naught, and we look forward to having the legal framework to be able to rectify this situation in the future.

The absence of a guideline tariff has created a vacuum for the HPCSA, who now have no reference for pronouncing on unethical billing. Under instruction from the Minister of Health, the HPCSA in August this year tabled for comment a new set of 'ethical tariffs' which was based on the 2006 RPL (read 'medical aid rate') plus an incorrectly calculated inflation percentage. The RSSA made a submission at a recent stakeholder meeting. The HPCSA has rescinded its decision on tariffs and the process will now restart. It is of interest to note, however, that no detailed ethical price list was tabled for specialist radiology.

\section{Interaction with funders}

The Medical Director interacts with medical schemes and administrators and other funders on a regular and as-needed basis.

Discovery Health and their administration arm have a 35\% share of the market and remain the major player in the private sector funding industry. Interestingly, the Discovery Holdings group is also the largest employer of actuaries in South Africa. It therefore goes without saying that our interactions with Discovery are not only the most important, but also that they are the most intricate and significant business partners on the one hand, but opponents on the other, as we as radiologists strive for best clinical care while Discovery focus on 'balancing the books'.

The intended revision of coding structure and tariffs via Department of Health projects has not come about for reasons outlined above. To rectify the situation, partial removal of the inherent crosssubsidisation has been achieved with some of the funders in this year's tariffs, and possibly next year as well, by applying differential increases to the high-tech and low-tech modalities. The affordability of high-tech imaging remains a concern, as well as the relatively low tariffs for general imaging and ultrasound. We continue to work on rectifying this situation.

Low-cost plans offered by the medial schemes are increasing in number and popularity. The insured population has increased from 7 million lives 4 years ago, to just over 8 million now. This growth has been brought about by the introduction of the low-cost plans, and the entrance of GEMS into the market, who have added approximately half a million previously uninsured government workers onto their medical aid, which now totals 1 million lives.

The industry has seen the merger of Metropolitan and Momentum administrators into MMI, which now administers just over a million lives as well. Consolidation of schemes and administrators is expected to continue. 
All medical schemes are witnessing an increase in the application of radiology - which matches international trends - and is mainly evident in CT and MRI, where the major advances in technology are being made. It is unfortunate that there are currently no direct measures of what we believe are downstream savings in total medical costs resulting from the higher imaging utilisation.

Over the last 3 years, we have seen an increase in the detailed assessment of individual radiology claims by third-party agents or the medical schemes themselves, as well as an increase in practice billing profiling. Overall practice profiling of radiology billing shows that, on the whole, most practices bill in accordance with accepted norms. The RSSA cannot support unsubstantiated billing outliers and will work to ensure appropriate billing practices.

Payments from the Compensation for Occupational Injuries and Diseases Act (COIDA) remain a major concern. The RSSA met with the Compensation Fund in September as part of the annual review process, where representatives of the Fund admitted that the change-over to the new SAP IT system had not gone as planned, and the system was not able to process in any measure IOD cases from 1 October last year. The RSSA has written to the Compensation Commissioner, urging intervention and requesting information on their plans going forward.

\section{SAMA and the SAPPF}

The RSSA has over the last 3 years made financial contributions to the South African Private Practitioners Forum to retain observer status. The SAPPF (an independent body) was formed by various specialist groups who were not satisfied that the South African Medical Association, and specifically its Specialist Private Practice Committee, were acting in the best interests of the specialists. The RSSA remains an independent association with no formal affiliation to SAMA or SAPPF.

\section{Clinical sub-groups}

The Paediatric Imaging Society was formed 2 years ago at the urging of Savvas Andronikou, the current chairman. The committee are congratulated on their start-up and continued good work. Tracy Kilborn is congratulated for arranging the RSSA-SASPI conference in conjunction with the CME Association. Included in the conference pack was the 'Doc Andy' booklet, the brainchild of Savvas. The RSSA funded the first publication run of the booklet, and complimentary copies are being distributed to teaching hospitals and radiology practices.

SAMSIG, the musculoskeletal imaging sub-group, continues its excellent work in promoting the discipline and education of musculoskeletal imaging. SAMSIG workshops provide a focused platform for this rapidly developing and growing sub-speciality. Thank you to chairman Richard de Villiers and the committee for their continued commitment.

SASNI (South African Society of Neuroradiology Imaging), chaired by Sally Candy, was inaugurated last year. The society is very active and holds regular clinical meetings. In July, the SASNI meeting in Cape Town was incorporated into the first RSSA 'webinar', with 60 on-line participants from around the country. SASNI is now also registered as a member of the World Federation of Neuroradiology Societies. Thank you to Sally and the committee.

The Interventional sub-group, headed by Coert de Vries, meets annually to conduct important peer review.
The PET-CT sub-committee challenged Discovery Health, via the Council for Medical Schemes, on Discovery's abuse of the PMB regulations, and the matter was resolved in favour of the service providers.

We hope that the webinar facility will encourage the activities of other groups.

\section{Communication}

Policy and decision making of the RSSA is done at council level; in-between council meetings, the work is done at the executive committee level. The Exco has remained unchanged for the last 4 years. Debate within Exco on matters to hand is robust.

With the advent of electronic communication, the reliance in earlier years of holding face-to-face meetings has diminished, and communication on most levels within the RSSA and its committees is done via email and teleconference. The RSSA website has become the hub for communications to members and I have no doubt that all members are pleased with the frequency and level of communication.

\section{The constitution}

Our constitution requires revision in many areas. Electronic communication makes superfluous the requirements for dormant regional sub-groups of the RSSA and related face-to-face meetings, each with their own committee structure. Proper and regulated succession planning for the ex officio posts should be included in a revised constitution. This is work for the year ahead.

\section{Secretary and secretariat}

Patricia Trietsch has sat at the secretary's desk for 20 years. Thank you, Patricia, for the years of good work, for responding to the phone calls and emails, and also for attending congresses and manning the RSSA desk in recent times.

A\&L Management Consultants have assisted the RSSA for the last 12 years, and provide invaluable support to the Exco and the Medical Director, and in recent times to the RSSA CME Association as well.

Trevor Allnutt and Jako Calitz are well-versed and -experienced in a broad range of radiology matters and provide input at many levels. Jako has been driving electronic communication of late, and we have all witnessed the increased communications via the website and the implementation of webinars for on-line workshop attendance. Emails in and out of the secretariat exceed 500 per week, excluding bulk email communications to members, which average close to 1 per day. They administer too all financial aspects of the RSSA and the CME association including tariff calculation work when necessary. In the last 2 years, the administration of the CME Association has been added to their activities. They have worked closely with the Medical Director and Congress Chair for many years, and their skills and understanding of all aspects of society work is significant. Their workload is growing, and they have increased their own support staff. A big Thank You to Trevor and Jako and their team.

\section{Medical Director}

Bates Alheit has held the post of Medical Director of the RSSA since its inception in 2004. He has given notice that he will not be available for the post after January 2013. The post has been advertised via the website, and interested persons are invited to apply via the RSSA office. 
We all need to takes our hats off and say a very big Thank You to Bates for the exceptional effort and good work that he has done on behalf of the members of the RSSA, and the radiology community at large, for so many years. I cannot do proper justice in this review in thanking Bates for the years of dedicated, selfless service. Bates became, with good reason, the face of radiology over the last decade. His knowledge of coding structures and tariffs, of technology and good clinical practice, his understanding of the bigger picture, his empathy for others, while at the same time having the courage to tackle what he knows is wrong, and his presence, in the moment and behind the scenes, has helped to place radiology very firmly as a respected discipline in the South African medical landscape. Bates, we thank you for all you have done for the profession, and wish you well in your retirement in this part of your career.

\section{In conclusion}

I stated at the beginning that we are experiencing changing times. Education in this county is at a cross-roads at the undergraduate level, and our academic departments and teaching hospitals will, I am sure, meet the challenge of ensuring that the quality and quantity of trained radiologists is at the required level to meet the desperate need for imaging resources in both the public and private sectors.

We all need to embrace whatever form the national health insurance will take. The current ratio of radiologists to the population does not support a healthy country, and we will no doubt all need to give, in the true sense of the word, in time and effort, until that ratio is corrected.

Academic programmes must continue to be supported by our worldclass continuing medical education activities, at the CME Association level, the clinical sub-group level, and with the continued publication of the SAJR. Keep up the good work.

Medical schemes remain the lifeblood of private practice. We need to partner with them, and at the same time challenge them, to ensure that our patients and their members receive appropriate clinical care while at the same time ensuring the sustainability of our cost-intensive practices.

Communication remains the key to any successful organisation. There will always be room for improvement. Communication is a twoway process and made so much easier in today's electronic environment. I encourage all members to contact the RSSA executive, committees, sub-groups and the secretariat regularly and on any matter. By hearing from you, we can improve the service to you.

My thanks again to Bates Alheit for his years of dedicated service on our Council and as Medical Director of the RSSA.

My sincere thanks also to Council members for their continued contribution, and special thanks to our executive committee members:

Vice President: Sheldon Godinho for his continued input in robust debate Past President: Richard Tuft for his experience and governance role Secretary: Mark Velleman for his work as secretary and as vice chair of SAMSIG

Treasurer: Thami Mngoma for his experience and urging to keep the spirit of ubuntu alive at Exco

Member without portfolio: Ashesh Ranchod for his continued voice of reason

Glen Buchanan for representing Gauteng radiologists

Academic representative: Professor Coert deVries for academic input and reason

Congress Chair: Professor Leon Janse van Rensburg again for his internationally recognised efforts in bringing us world-class congresses.

2013 will be another RSSA election year, and I will not be standing again for President. I urge members interested in the work and governance of the RSSA to put their names forward for office. We need member involvement to determine the future direction of the society, and we need those who are prepared to serve in official positions to volunteer.

May I wish all RSSA members in private and public posts success in 2013.

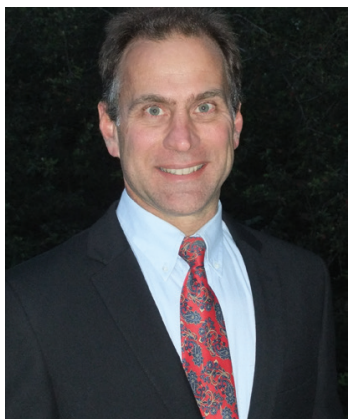

Clive Sperryn

(President, RSSA) 